\title{
Check in Check out Using Blue Tooth Ad Hoc Network (CICO-BT)
}

\author{
P. K. Bishnoi \\ Department of CSE Faculty of E \& T \\ Mody Institute of Technology and Science \\ Lakshmangarh (Rajasthan) India
}

\author{
P. K. Das \\ Department of CSE Faculty of E \& T \\ Mody Institute of Technology and Science \\ Lakshmangarh (Rajasthan) India
}

\begin{abstract}
In this era of information technology, enterprise needs the automation of every business process to get the competitive advantage and multidimensional growth of the business. For this every enterprises need to observe the incoming and out going time of every employee and to stop the entry of unauthorized persons. For CICO many automated and manual systems are available like smart card, RFID, manual ID card, thumb impression techniques, etc. Every technique has its advantages and disadvantages. But the biggest problems with people /employee in this IT era is that employees have to carry a number of electronic devices (PDA, Mobile Phone, Smart card, Client for RFID, Library card, ATM Card, Credit Card etc) with them for different purposes. Carrying so many e-devices/e-cards is not comfortable for a person. To reduce the number of e-devices one has to carry, many IT/Electronic industries are working towards integration. As a result, mobile phone today can be used for MP3/MP4 player, FM radio, storing data, surfing Internet and much other application in business transactions etc.

The purpose of this paper is to integrate the authentication process at the time of entry and exit of employee using mobile phones with the support of Bluetooth (BT) Ad-Hoc network.

Today the cost of BT enabled mobile is not very high. The minimum cost of a BT and Kilobyte Virtual Machine (KVM) mobile is Rs.2500/- and an employee can easily afford it. An analysis report says that $-95 \%$ employees are having BT and KVM mobiles. It means mobile phone can be used as an ID card also for the purpose of authentication in CICO system.
\end{abstract}

\section{General Terms}

Kilobyte Virtual Machine, Motion Detection, Biometric System

\section{Keywords}

CICO; BT; PDA; KVM; RFID; PDA

\section{INTRODUCTION}

CICO BT is an abbreviation for "Check In Check Out using Blue tooth ad-hoc network" A team of software analysts observed and analyzed that check in check out is a very intricate issue for every organization. It is available at organization in various forms. Doing check in check out manually is very time consuming, and requires number of documents and extensive paper work. CICO BT provides a very easy solution of check in check out in the form of software and hard ware. It can be implemented with exiting infrastructure and integrated with legacy system. The basic concept behind CICO BT, a Bluetooth enabled mobile is used as an identity of the owner of the mobile phone. It provides solution for the entry and attendance of employees of the organization and the daily visitors. But the employee of the company is to be registered in advance where as the visitors or guests are to be registered in real-time. After registration, whenever the employee enters the company premises, the BT server searches and makes an ad-hoc wireless connection with the Bluetooth enabled mobile phone of the employee/user/visitors and get the BT address of the same for entry. This process takes the attendance of the registered employee without any initialization from the employee/visitor/user.

To make the system more secure, robust and to avoid the exchange of mobile by employee for attendance, a camera is integrated with the CICO BT. The process of making the wireless ad-hoc connection and getting the BT address of the mobile is initialized on the event of motion detection by the camera. Due to the presence of motion detection event BT server has not to search continuously for a long time whenever an employee/ guest/visitor comes, the BT search will be started. A small, program will be installed in the PC/Laptop of every authority of the organization, that will search the BT devices in the range and transmit to the central application server. So the concerned authority of the organization can get the waiting list of visitors. Software can also search peoples in a centralized way to find out where a person is now. Event it gives the complete route of the person to the administrator. It may be used at multiple organizations of different categories. Software part of the project is very robust and secure achieved through the process of authentication and authorization. The system has the concept of alarm generation also. If Motion is detected but no BT is found, a negative alarm will be generated. If BT is found but not registration was done a different alarm will be given. Only registered and BT -enabled phone owners can get the entry to organization. Latest tools and technologies have been used for the implementation of the system. (These are Sun Java Wireless Toolkit, NetBeans Mobility and J2EE IDE, KVM and BT -enabled Mobile Phones, Oracle 10g, Bluecove, Java Media Framework)

\section{REVIEW \& ANALYSIS}

An analysis says there are some existing systems like manual without ID card, manual with ID card Smart Card (Contact and Contact less), Bar code, Bio metric System (Thumb Impression, Face recognition and Iris recognition etc). Manual without ID card is fully trust base and human memory based system. In this system no ID cards are issued and the system is dependent on the memory and recognition power of the human mind. It has few advantages like being very cheap and no hardware or software is required but 
it also has many disadvantages like not being reliable, not secure, no documentary proof, human memory dependent, and is thus suitable for home or small industries etc.

Manual ID card based CICO System has an ID card with name and other information about the candidate. ID card should also have proper information about the employer with the authorized signature. At the time of authentication the security man at the entry of the organization verifies information of the ID card manually. Same process will be applied at the time of entry and exit. It has some advantages like being cost effective, easy to implement., no specific training is required, no specific devices are required but has the disadvantages that it is non electronic, non versatile etc.

In biometric security system some techniques like face recognition, thumb impression and iris recognition are used. It also has its own advantage and disadvantages. We will now discuss in detail some other technologies available the market.

\subsection{Bar Code Technology}

A Bar Code is just another way of encoding numbers and letters by using a combination of bars and spaces of varying widths. This is another way of entering data into a computer. A bar code does not contain descriptive data. It is a reference number that a computer uses to look up an associated record that contains descriptive data and other important information. When the cashier scans this number, it is transmitted to the computer, which finds the record associated with that item number in the database. The matching item record contains a description of the product, vendor name, price, quantity-on-hand, etc

There are many bar code readers such as -Pen Type Readers or Bar Code wands: Laser Barcode Scanners, CCD Barcode Scanners, and Camera Based Barcode Readers. Advantages of the keyboard wedge: Simple and easy to interface to the computer. No software is required. Disadvantages of the keyboard wedge are:

1.When you scan a bar code, the cursor has to be in the correct input data field, and in the correct application otherwise the bar code data will end up in whatever application that is active at that time. This can cause all sorts of problems.

2. The keyboard output is limited, in the sense that you cannot modify the data in any way before sending it into the program in the computer. Advantages of Bar code reader with RS232 or "Serial Interface": 1. This type of bar code reader is connected to an available serial port on the back of the computer. 2. When a bar code is read, one has control over how and where the data goes.

3. One can perform any modifications on the bar code data before sending it to the computer or translating the data. Disadvantages of Bar code reader with RS232 or "Serial Interface": It is more complex than the keyboard wedge $[1,2]$.

\subsection{RFID Technology}

RFID is the reading of physical tags on single products, cases, pallets, or re-usable containers that emit radio signals to be picked up by reader devices. Tags contain a unique identification number called an Electronic Product Code (EPC), and potentially additional information of interest to manufacturers, healthcare organizations, military organizations, logistics providers, and retailers, or others that need to track the physical location of goods or equipment. All information on RFID tags, such as product attributes, physical dimensions, prices, or laundering requirements, can be scanned wirelessly by a reader at high speed and from a distance of several meters.
Advantages of RFID vs. barcode technology: No line of sight requirement, the tag can stand a harsh environment, long read range, portable database ,multiple tag read/write, tracking people, items, and equipment in realtime.[9]

\subsection{Biometrics Technology}

There are two main modules in a biometrics system. "storing" and "comparing". The systems must first store your information before it can use this stored information to compare and verify. The storing process however differs between different systems. Once this storing process is done, the "comparing" process is done daily or as and when required. Advantages of a biometrics system: The fact that one will have to be personally present in order to authenticate oneself is the advantage of this system. Fingerprint or retina of the eyes of one person does not match with anyone else's data in the database. Therefore there is absolutely no chance of other people misusing the identity. Disadvantages of a biometric system: The fingerprint of people working in Chemical industries is often affected. Therefore these companies should not use the finger print mode of authentication. Biometrics is also an expensive security solution. $[3,4]$

\section{FLOW CHART AND DESIGN}

An ad-hoc network is one that consists of independent wireless nodes that have the ability to dynamically form connections with each other to create a network. An ad-hoc network does not require any central node: a slave and a master. Each node has the ability to be either or both at the same time requests or reports to a central authority. Whenever a candidate will enter the organization, BT search module asks for the registration via an event of motion detection of camera. If the discovery system replies an unregistered user, registration will be made. Otherwise candidates will be allowed to enter. (Fig. 3.1)

Now the candidate will be asked for the guest or new employee. If candidate replies that he is a guest, he will be sent for registration. If the candidate replies that he is a new employee, he will be sent to the employee registration system. After registration he will become an authorized employee or guest of the organization. Later, whenever he comes to the organization or leave the organization every time on the motion detection event of camera BT discovery will be started and the time of entry and exit will be recorded to database. The incoming and out going entry will be detected with two different cameras separately. (Fig 3.1)

\begin{tabular}{|l|l|l|}
\hline Layer & SW & HW \\
\hline PDA & KVM & $\begin{array}{l}\text { Bluetooth in mobile } \\
\text { phone }\end{array}$ \\
\hline BT discoveries & $\begin{array}{l}\text { JMF, Bluecove } \\
\text { and Vision } \\
\text { Framework }\end{array}$ & $\begin{array}{l}\text { BT with Widcom or } \\
\text { MS BT stack, Web } \\
\text { Cam }\end{array}$ \\
\hline Application & $\begin{array}{l}\text { Tomcat 4.1 or } \\
\text { above } \\
\text { JDBC middleware } \\
\text { for Oracle 10g }\end{array}$ & $\begin{array}{l}\text { Server with 1GB } \\
\text { RAM, Core 2 Duo, } \\
\text { 20 GB H.D. }\end{array}$ \\
\hline Database & Oracle 10g Server & $\begin{array}{l}\text { Server with 1Gb } \\
\text { RAM, Core 2 Duo, } \\
\text { 20 GB H.D. }\end{array}$ \\
\hline
\end{tabular}




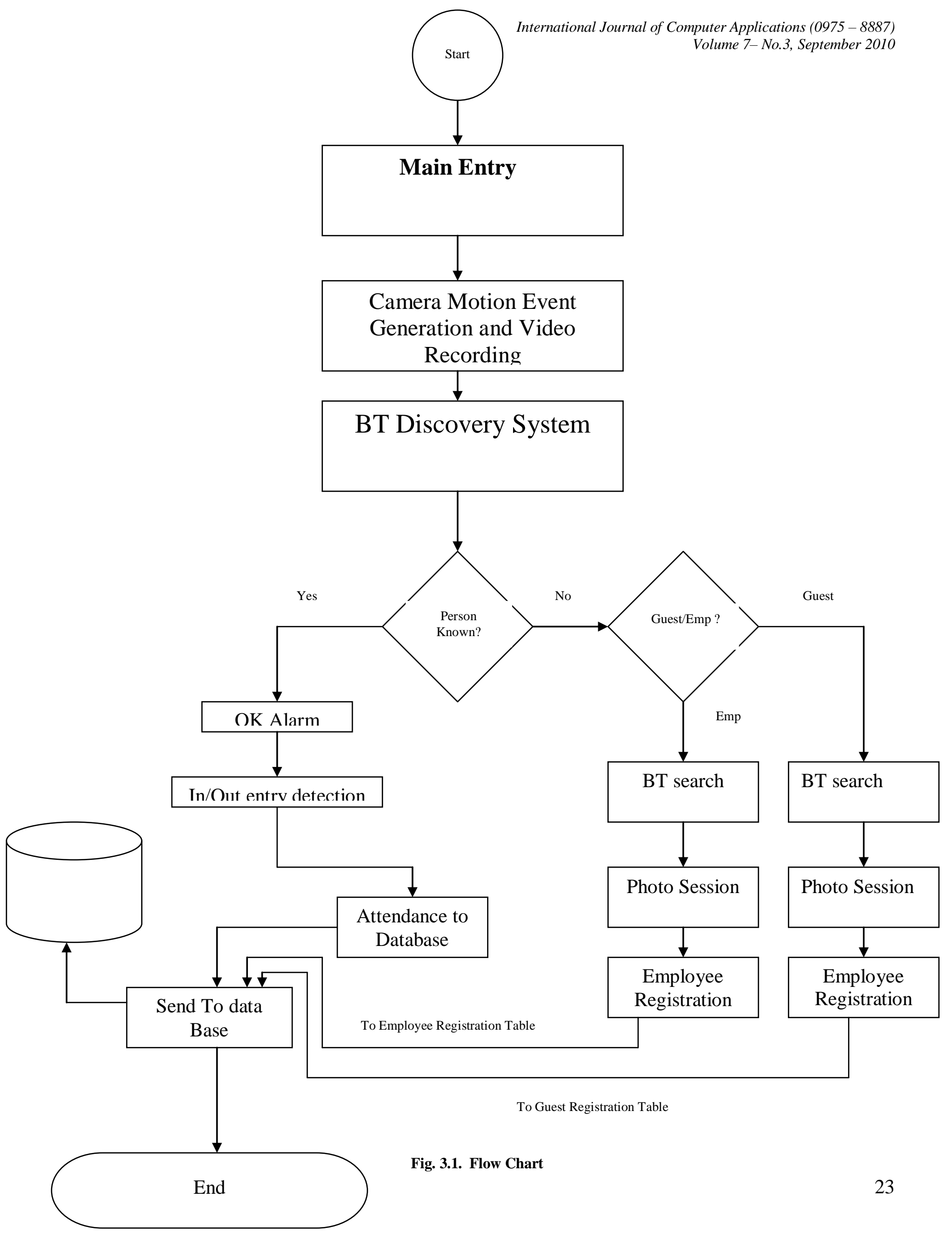




\section{ELECTRONIC MODEL AND ARCHITECTURE OF CICO BT WITH REALIZATION}

Electronic model has three servers Database server Oracle $10 \mathrm{~g}$, Application server tomcat 4.1 and DNS server. For the natural feeling of an intergalactic multi-tier application desired domain name is registered at a local DNS server. Domain name will be mapped to the IP address of Application server. Here we registered http://www.cicobt.com on DNS server. The IP of application server Tomcat 4.1 is 10.20 .111 .170 . (Fig. 4.1)

So whenever a user makes a request, it request come to the DNS server for the registered IP. After supplying the corresponding IP address the connection with the application server will be established and the default page will be served. That is the home page of the web application. Now if incoming request need database access, connection with the JSP page to Database Server Oracle $10 \mathrm{~g}$ will be established and the intended data will be replied and served. Application server will have JSP/Servlet pages for the implementation of all security, centralized control, administration and other registration facilities.

Another very important module of the software is BT discovery at the main door of the organization. This module does the discovery of BT device on the motion detection event of two different incoming and outgoing video cameras. Main door unit has one speaker also to give an audible alert on the discovery of BT device. It will generate three different types of alert on different incoming information by camera and BT searches. Like BT search for already registered "First Type". Secondly BT searches for not registered "Second Type" and if BT is off "Third Type". Main door unit also has a system for registration and photo session.

Employee registration system has the camera and one BT discovery system for the registration of employee. Because at the time of registration of employee the BT device name and MAC address of mobile will be registered with the other information of employee/visitor/candidate.

Every authority will have PC with/without the camera but with a BT discovery hardware essentially. This will search the BT device of local range. If device is found multiple times like five times, it will be considered that the person is waiting for that authority.(Fig. 4.1)

\subsection{Embedding Security And Privacy}

By the point of view of security and privacy the following points were observed and implemented. These cover the security and privacy to large extents as per the requirements of the system.

- Registration of every employee with a user name and password.

- Password can be changed after the registration under observation of administrator.

- Registration of every employee in a particular category.

- At the time of every resource's request password and user name will be verified by the session variables.

- Registration of every authority with IP of PC for tracking of guest in organization.

- Synchronization of video with BT detection and IP addition of authorized PCs to database.

- PC authentication at the time of software access.
- Registration of every resource (web page) in database.

- Allow/disallow the page to a particular category.

- Checking of page authentication at the user request.

- Maintaining the session with server.

- Encryption of database

To catch fraud and cheating, privacy and security is also help. But if some wrong thing has happened, to investigate it the audit trail has been implemented. Whenever the client and server communicate on recommended standards, the client sends information about itself, viz., name of client, IP address etc. So this information is to be retrieved and to be stored at the server side in database table for future use. Not only this, the client is also sending other client request variables values in the body part using the POST method.

1. Using request object the IP address/MAC address etc is to be retrieved and sent to database with time, date, URL and URI etc.

2. By maintaining the session variable the user name will also be send to application server to store in to database.

So if anybody tries the user name and password, immediately that event will be recorded in a log file.

CICO BT project also takes care about possible exchange of mobile, resource security, attempt to alter the information at server, blocking IP, user authentication, encryption and decryption from the security point of view.

\section{RESULTS AND ANALYSES}

\subsection{Advantages}

ㅁ Easy to use

a Robust

a Global management

․ Integrated Privacy and security

口 Audit trail

a Implementation with existing infrastructure

- Nothing is to be initialized from the user side

口 Tracking of guest/visitor /employee

a Waiting List display

․ Synchronization of web cam video with BT discovery

a Long term solution

口 Performance of the system is directly proportional to BT speed research.

口 WWW administration

\subsection{Limitations}

- Speed of blue tooth

Exchange of mobile phone can be investigated but can not be stopped

- Limited number of devices can be entertained at the same time

- Every employee should have a BT enable mobile phone

口 BT of mobile should 'remain on' at the time of entry or exit 


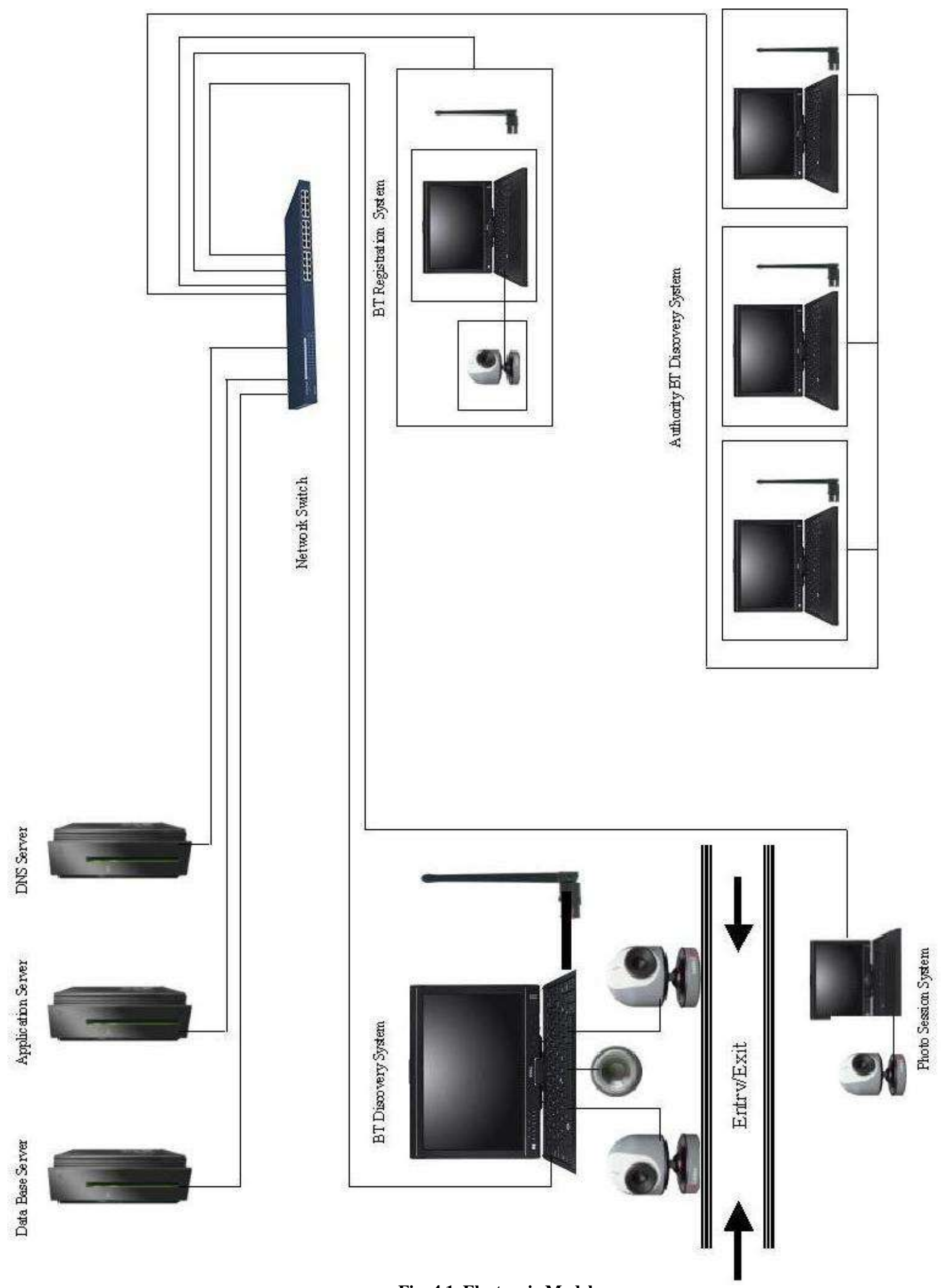

Fig. 4.1. Electronic Model 


\section{a Audit Log}

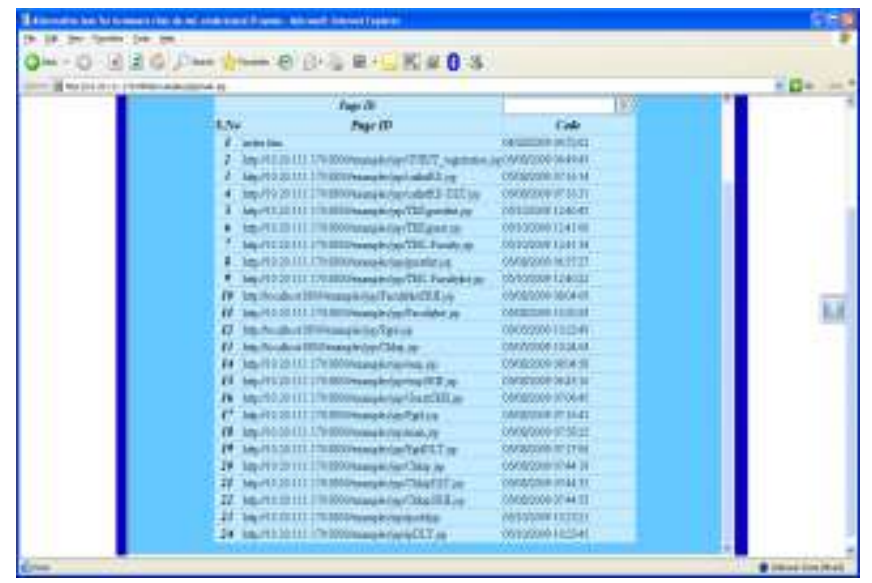

\section{ㄴogin Screen}

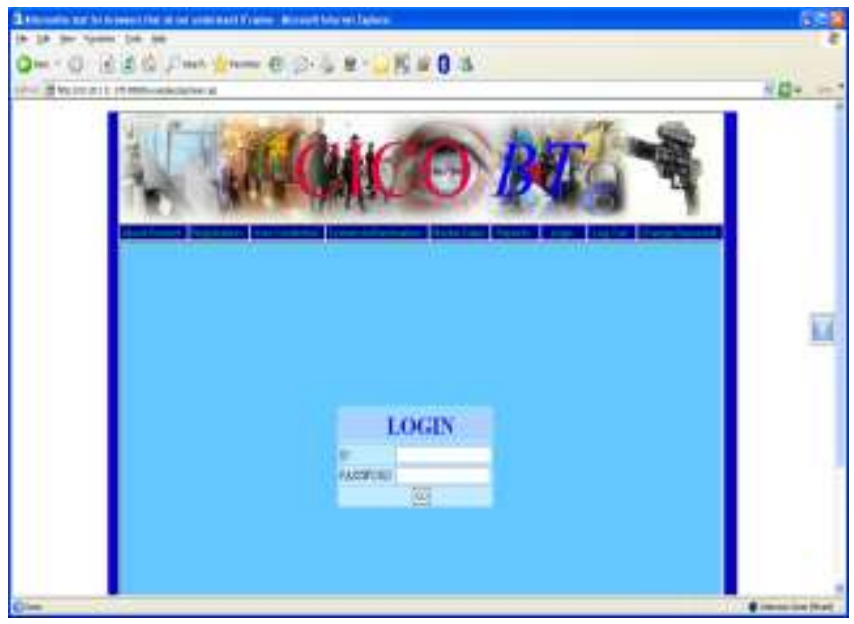

\section{a Employee Registration}

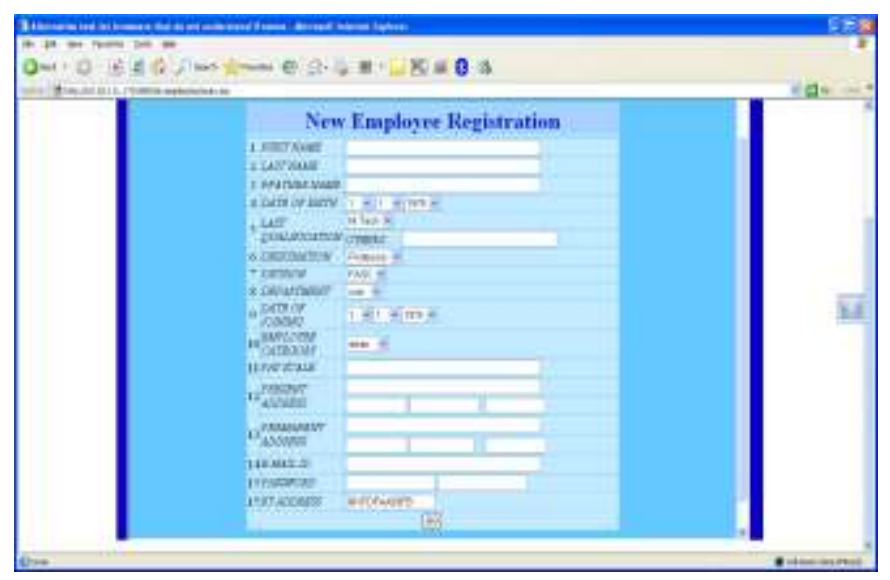

\section{ㄴ User Credential}

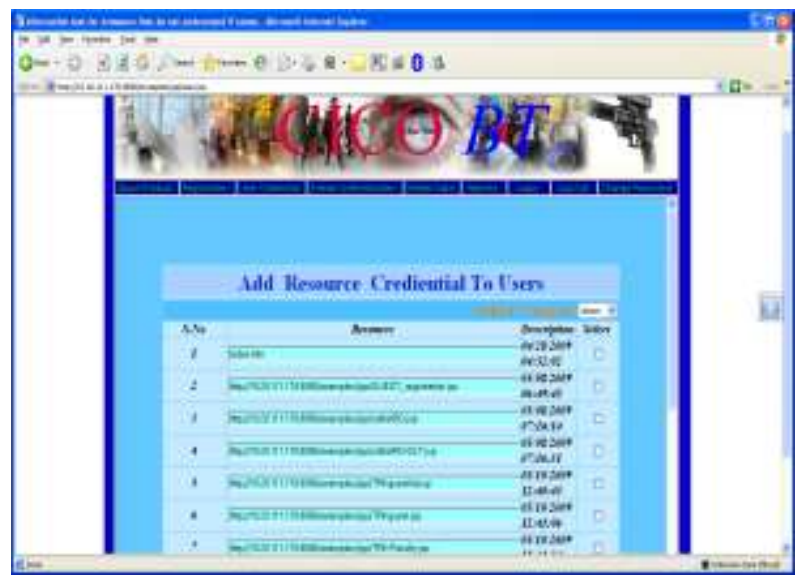

For testing of the completed system, algorithms implemented and the communication model following devices were used.

1. Dev1. Laptop Lenovo Intel ${ }^{\circledR}$ Core ${ }^{\mathrm{TM}} 2$ Duo CPU T64000@2.00GHz $897 \mathrm{MHz}, 1.96 \mathrm{~GB}$ of RAM with MS Windows XP with service pack 2. With BT V2.1

2. Dev2. PC Intel® D CPU 3.00GHz $2.99 \mathrm{GHz}, 1.99$ GB of RAM with MS Windows XP with service pack 2. With BT V2.1

3. Dev3. Nokia $3110 \mathrm{C}$ with Bluetooth v2.0 (with A2DP) Advanced Audio Distribution Profile. Speed: $3 \mathrm{Mbps}(3$ times of 1.2 Version)

4. Dev4. Nokia 2700 C with Bluetooth v2.0 (with A2DP) Advanced Audio Distribution Profile. Speed: $3 \mathrm{Mbps}(3$ times of 1.2 Version)

\begin{tabular}{|c|l|l|l|l|}
\hline S.No & $\begin{array}{l}\text { Devic } \\
\text { e }\end{array}$ & $\begin{array}{l}\text { Destination } \\
\text { Devices }\end{array}$ & $\begin{array}{l}\text { Search } \\
\text { Time(Sec) }\end{array}$ & $\begin{array}{l}\text { No. of } \\
\text { Device } \\
\text { s }\end{array}$ \\
\hline 1 & Dev1 & Dev2 & 7 & 1 \\
\hline 2 & Dev1 & Dev2, Dev3 & 5 & 2 \\
\hline 3 & Dev1 & Dev2, Dev3, Dev4 & 6 & 3 \\
\hline 4 & Dev2 & Dev1 & 14 & 1 \\
\hline 5 & Dev2 & Dev1, Dev3 & 14 & 2 \\
\hline 6 & Dev2 & Dev1, Dev3, Dev4 & 14 & 3 \\
\hline 7 & Dev3 & Dev1 & 10 & 1 \\
\hline 8 & Dev3 & Dev1, Dev2 & 15 & 2 \\
\hline 9 & Dev3 & Dev1, Dev2, Dev4 & 17 & 3 \\
\hline 10 & Dev4 & Dev1 & 12 & 1 \\
\hline 11 & Dev4 & Dev1, Dev2 & 14 & 2 \\
\hline 12 & Dev4 & Dev1, Dev2, Dev3 & 15 & 3 \\
\hline
\end{tabular}

Table: 5.1 
Above table 5.1 shows the time of search of different devices in the personal area. In most of the cases the large number of devices take more time in the search in comparison with single device or small number of devices. After that the device will collect the list of files available and the time of transfer of the selected file. Time of transfer depends upon the speed of data transfer of BT version. So total time TFGT (total file getting time) of collecting one specified file of size SF and the size of list SL and the searching of all the devices is TL

$$
\mathrm{TFGT}=\mathrm{SF} / \mathrm{SBT}+\mathrm{SL} / \mathrm{SBT}+\mathrm{TL}
$$

\section{CONCLUSION \& FUTURE DIRECTIONS}

Today the speed of BT is very limited in the sense of establishing the BT ad-hoc wireless connection between PC and mobile phone. Due to this the MAC address identity-retrieving process become sluggish. After launching the incoming version 3.0, this problem will be resolved. It is under research. CICO-BT system can be made more reliable and secure by integration with biometric system. The system is very useful for organizations and enterprise requiring check in check out. If the government changes or reengineers the working and security policies, the system may be changed very easily. It is capable of tracking a person at campuswide level. The software may become very useful for military application in terrorism control also. This is sure the project may be very constructive and flourishing, because it is sturdily based on the user need and innate fundamental.

\section{ACKNOWLEDGMENTS}

Authors want to thank to the CSE Departments of MITS, authorities and management of MITS University for providing the research facilities and environment for this research.

\section{REFERENCES}

[1] "Advantages of BarCode" [Online] Available http://www.articlealley.com/
[2] "BarCode Scanner" [Online] Available http://www.semicron.com.

[3] "Biometric" [Online] Available http://en.wikipedia.org/wiki/Biometrics

[4] "Biometrics Security" [Online] Available http://www.allpctips.com/2009/12/13/biometrics/.

[5] "Bluetooth technology". [Online]. Available: http://www.bluetomorrow.com /index.php? option= com_frontpage\&Itemid=1.[Accessed: March 09, 2009].

[6] "Bluetooth: Low Power and Low Cost". [Online]. Available: http: //www.bluetomorrow.com. [Accessed: March 09, 2009].

[7] "High Speed Bluetooth" [Online]. Available: http://www.bluetomorrow.com /content/section / 344/466/. [Accessed: March 09, 2009].

[8] "I frame,". [Online]. Available: http://htmlhelp.com. [Accessed: March 09, 2009].

[9] "RFID Smart Cards" [Online] Available http://rfid.bemrosebooth.com

[10] Bruce Hopkins, Ranjith Antony, Bluetooth for Java. Apress, 2003.

[11] David Blankenbeckler "An Introduction to Bluetooth" [Online]. Available: http://www.wirelessdevnet.com /training/channels/bluetooth/features/bluetooth.html. [Accessed: Feb 06, 2009].

[12] James Keogh, The Complete Reference: J2ME. TataMcGraw- Hill, 2003.

[13] Jonathan Gennick, Carol McCullough-Dieter \& GerritJan Linker, Oracle 8i DBA Bible. IDG Book India, 2002.

[14] K.A.C. Dushamali1, V.I.R. Fernando2, Ravindya Samarakoon3 Udayanthi Weerasooriya4 "Student Information Access System Via Bluetooth" Second International Conference on Industrial and Information Systems, ICIIS 2007, 8 - 11 August 2007, Sri Lanka [pp. 393-397]

[15] Rick Greenwald, Robert Stackowiak \& Jonathan Stern Oracle Essentials. O'Reilly III ${ }^{\text {rd }}$ Edition. 